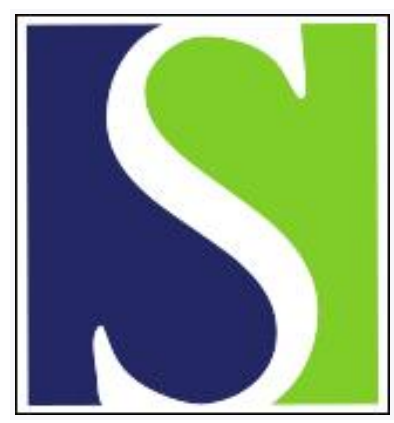

Scand J Work Environ Health 2020;46(3):229-230

https://doi.org/10.5271/sjweh.3893

Published online: 31 Mar 2020, Issue date: 01 May 2020

The COVID-19 (Coronavirus) pandemic: consequences for occupational health

by Burdorf A, Porru F, Rugulies R

Affiliation: Department of Public Health, Erasmus Medical Center, Rotterdam, The Netherlands. a.burdorf@erasmusmc.nl

The following articles refer to this text: 2021;47(4):245-247;

2021;47(5):408-409; 2021;47(5):349-355; 2022;48(1):61-70;

2022;48(5):327-350; 2023;49(3):182-192; 2023;49(3):165-169; 0;0

Special issue:0

Key terms: coronavirus; COVID-19; editorial; occupational health; occupational health; pandemic

This article in PubMed: www.ncbi.nlm.nih.gov/pubmed/32356896 


\section{The COVID-19 (Coronavirus) pandemic: consequences for occupational health}

We live in unprecedented modern times experiencing how an outbreak of a particular viral disease, COVID-19, caused by SARS-CoV-2, also commonly referred to as the Coronavirus, is disrupting societies and personal lives. The virus is likely to spread to most, if not all, countries, illustrating the interconnectedness of the world. At the time of writing, Italy and Spain have become the epicenters in terms of fatalities in Europe, whereas the United States has recorded the most diagnosed cases worldwide. While many national measures to contain, suppress, mitigate, or delay the spread of the virus are being taken, there is great uncertainty as to which measures are appropriate or not, varying from instructions of stringent hand hygiene; travel restrictions; social distancing; and closure of schools, restaurants, bars and shops to a complete lock down of large parts of society. Science-based evidence informing the policy about the efficaciousness and possible adverse effects of these measures are urgently needed. As there is a lack of both data and insight into the mechanisms of the pandemic, generating this science-based evidence will take some time. Key epidemiological numbers, such as the attack rate of the disease and the infection-hospitalization and infection-fatality ratios, are not yet available, and estimates based on the existing limited data come with huge uncertainties $(1,2)$. Thus, scientists blindfolded by the lack of data have to inform a policy that needs to decide about far-reaching measures fundamentally changing societies and individuals' lives. It's an uncomfortable situation.

COVID-19 is a tremendous challenge for occupational health. Workers in many occupations are facing high risks of becoming infected. There is a long list of jobs that involve direct contact with the public and close physical proximity to others. Workers in shops, bars, restaurants, fast food, and delivery services are at increased risk for exposure to infected persons due to the large number of daily contacts. Barbers, manicurists, and physical therapists work in close proximity to their customers. However, there are also many jobs where workers have the freedom of being able to work from home, thus considerably reducing the risk to contract the virus. For example, the authors of this editorial are working from home, but communication is easy through email and Skype.

Without any doubt, healthcare personnel deservedly receive nationwide attention these days. They are at the forefront of combatting this outbreak. Not only is their work stress at record high, their healthcare organizations are under severe pressure and many are struggling to cope with care needs of so many critically ill patients simultaneously. Healthcare professionals are at increased risk of exposure to high viral load because of their close contact with COVID-19 patients, which puts them at risk of becoming infected. At the same time, they themselves are an important source of transmitting the disease to colleagues, patients, friends, and family. Healthcare workers cannot stay at home in times of capacity problems in health emergencies. In a recent letter, a physician asked himself the question: "Am I part of the cure, or am I part of the disease?" (3)

Early evidence from Wuhan, the origin of the worldwide outbreak, indicated that - of all Coronavirus infected cases - almost $4 \%$ had comprised healthcare personnel, and five deaths among healthcare workers had been confirmed (4). In Italy, the most affected country in Europe, on March 26, 2020, it was reported that more than 5,000 healthcare workers had tested positive for the Coronavirus and more than 40 had died as a result of COVID-19 (5). The daily reality in Italian hospitals is grim: insufficient testing capacity, lack of suitable protective equipment, lack of mechanical ventilators, wards not isolated from each other, and patients in beds in corridors. The capacity of the national health system is stretched to its limits and, in the most affected region of Lombardy, clearly insufficient (6). In such a crisis, it is imperative to ensure that healthcare workers are protected, for their own safety and to safeguard the healthcare system but also to prevent transmission of the virus. It is obvious that we have to revert to the proven strategies to protect workers by creating awareness of risks and providing personal protective equipment as well as appropriate hygiene procedures. Almost 15 years ago, prompted by the SARS epidemic, Descatha and colleagues (7) already pleaded for such contingency plans in healthcare in the event of an influenza pandemic. 
Companies will have to deal with the psychosocial and psychological consequences of the current Coronavirus outbreak. Specifically, healthcare organizations will need to deal with insomnia, burnout, depressive symptoms, and post-traumatic stress disorders among healthcare workers. In Wuhan hospitals support teams have been set up to provide individual psychological guidance and group-based interventions (8). An important source of psychological distress are the impossible decisions (who to treat first?) under extreme work pressure. A recent analysis of previous major incidents called not only for peer-support programs during the crisis but also for active monitoring and adequate availability of mental treatment to prevent long-term damage to healthcare staff (9).

The long-lasting societal effects of this pandemic are impossible to estimate yet. National, regional or global economic recessions seem to be inevitable. We know from previous economic crises, such as the recession in Finland in the 1990 s (10) and the global financial crisis of 2007-2009 $(11,12)$ that there were marked effects on people's health, both on those who lost their jobs and those remaining at work. Thus, efforts on containment, suppression and mitigation are not only needed with regard to the virus but also with regard to possible adverse societal and economic consequences.

COVID-19 will have both a short-term and long-lasting impact on societies, healthcare systems, workplaces and individuals alike. As occupational health professionals we must contribute with our knowledge and insights to provide appropriate occupational health for all workers affected directly and indirectly by this pandemic.

\section{References}

1. Ioannidis JPA. A fiasco in the making? As the coronavirus pandemic takes hold, we are making decisions without reliable data. STAT; 2020, March 17. https://www.statnews.com/2020/03/17/a-fiasco-in-the-making-as-the-coronavirus-pandemic-takes-hold-we-aremaking-decisions-without-reliable-data/

2. Lipsitch M. We know enough now to act decisively against Covid-19. Social distancing is a good place to start. STAT; 2020, March 18. https:/www.statnews.com/2020/03/18/we-know-enough-now-to-act-decisively-against-covid-19/

3. Rose C. Am I part of the cure or I am part of the disease. N Engl J Med 2020, March 18 (Epub ahead of print). https://doi.org/10.1056/ NEJMp2004768

4. $\mathrm{Wu}$ Z, McGoogan JM. Characteristics of and important lessons from the coronavirus disease 2019 (COVID-19) outbreak in China: summary of a report of 72314 cases from the Chinese Center for Disease Control and Prevention. JAMA 2020, February 24 (Epub ahead of print). https://doi.org/10.1001/jama.2020.2648

5. Giuffrida A, Tondo L. 'As if a storm hit': more than 40 Italian health workers have died since crisis began. The Guardian. 26 March 2020. https:/www.theguardian.com/world/2020/mar/26/as-if-a-storm-hit-33-italian-health-workers-have-died-since-crisis-began.

6. Remuzzi A, Remuzzi G. Covid-19 and Italy: what next? Lancet 2020, March 12 (Epub ahead of print). https://doi.org/10.1016/501406736(20)30627-9.

7. Descatha A, Dolveck F, Salomon J. A contingency plan for health care worker protection in the event of a flu pandemic. J Occup Environ Med 2006;48:660-1. https://doi.org/10.1097/01.jom.0000226919.79483.b7

8. Kang L, Li Y, Hu S, Chen M, Yang C, Yang BX et al. The mental health of medical workers in Wuhan, China dealing with the 2019 novel coronavirus. Lancet Psychiatry 2020;7:e13-e14. https://doi.org/10.1016/S2215-0366(20)30047-X

9. Greenberg N, Docherty M, Gnanapragasam S, Wessely S. Managing mental health challenges faced by healthcare workers during covid-19 pandemic. BMJ 2020;368:m1211. https://doi.org/10.1136/bmj.m1211

10. Vahtera J, Kivimäki M, Pentti J. Effect of organisational downsizing on health of employees. Lancet 1997;350(9085):1124-8. https:// doi.org/10.1016/S0140-6736(97)03216-9

11. Karanikolos M, Heino P, McKee M, Stuckler D, Legido-Quigley H. Effects of the global financial crisis on health in high-income OECD countries: A narrative review. Int J Health Serv 2016;46:208-40. https://doi.org/10.1177/0020731416637160

12. Torá I, Martínez JM, Benavides FG, Leveque K, Ronda E. Effect of economic recession on psychosocial working conditions by workers' nationality. Int J Occup Environ Health 2015;21:328-32. https://doi.org/10.1080/10773525.2015.1122369

Alex Burdorf and Fabio Porru

Department of Public Health

Erasmus Medical Center Rotterdam

Rotterdam, The Netherlands

[Email: a.burdorf@erasmusmc.nl]
Reiner Rugulies

National Research Centre for the Working Environment (NFA)

Department of Public Health and Department of Psychology,

University of Copenhagen

Copenhagen, Denmark

[email: rer@nfa.dk] 